Archives de sciences sociales des religions

112 | octobre-décembre 2000

Âme et corps : conceptions de la personne

PERRET (Marie-Antoinette), Une vocation paradoxale.

Les instituts séculiers féminins en France (XIX ${ }^{e}-X X^{e}$ siècles)

Paris, Cerf, 2000, 414 p. (avant-propos de Mgr Paul-Marie Guillaume ; préface par Claude Langlois) (coll. « Cerf-Histoires »)

Jean Séguy

\title{
OpenEdition
}

Journals

Édition électronique

URL : http://journals.openedition.org/assr/20349

DOI : 10.4000/assr.20349

ISSN : $1777-5825$

Éditeur

Éditions de l'EHESS

Édition imprimée

Date de publication : 31 décembre 2000

Pagination : 118-119

ISBN : 2-222-96698-1

ISSN : 0335-5985

Référence électronique

Jean Séguy, «PERRET (Marie-Antoinette), Une vocation paradoxale. Les instituts séculiers féminins en

France (XIXe-XXe siècles)", Archives de sciences sociales des religions [En ligne], 112 I octobre-décembre 2000, document 112.42, mis en ligne le 19 août 2009, consulté le 21 septembre 2020. URL : http:// journals.openedition.org/assr/20349; DOI : https://doi.org/10.4000/assr.20349

Ce document a été généré automatiquement le 21 septembre 2020

(C) Archives de sciences sociales des religions 


\section{PERRET (Marie-Antoinette), Une vocation paradoxale. Les instituts séculiers féminins en France (XIX ${ }^{e}-X X^{e}$ siècles)}

Paris, Cerf, 2000, 414 p. (avant-propos de Mgr Paul-Marie Guillaume ; préface par Claude Langlois) (coll. « Cerf-Histoires »)

Jean Séguy

\section{RÉFÉRENCE}

PERRET (Marie-Antoinette), Une vocation paradoxale. Les instituts séculiers féminins en France (XIX ${ }^{e}-X X^{e}$ siècles), Paris, Cerf, 2000, 414 p. (avant-propos de Mgr Paul-Marie Guillaume ; préface par Claude Langlois) (coll. « Cerf-Histoires »)

1 Le canon 710 du nouveau code (1983) définit l'« institut séculier » comme " institut de vie consacrée dont les membres vivant dans le monde tendent à la perfection de la charité et s'efforcent de contribuer de l'intérieur à la sanctification du monde ». On ne saurait mieux dire ; mais on peut le dire autrement avec les mots de Cl. Langlois dans la préface : ces groupements de consacrés se situent entre « la prolifération congréganiste triomphante en France au XIX ${ }^{\mathrm{e}}$ siècle... et l'essor du laïcat, perceptible de plus en plus au $\mathrm{XX}^{\mathrm{e}}$ siècle, J.S. -) à travers la multiplication des mouvements de jeunesse, l'affirmation de l'Action catholique, l'émergence de la spiritualité conjugale ». M.-A.P. est amenée à le préciser plus loin, les instituts en question constituent des réponses ecclésiastiques à certaines situations de persécutions (dès 1793 et à d'autres dates, en France) ainsi qu'à la situation de sécularisation des sociétés occidentales depuis la Révolution française en tout cas, 1880 marquant ici un point-charnière. Curieusement la «sécularité » est considérée aujourd'hui comme une «valeur » par les intéressés. 
Mais mener une vie séculière n'équivaut pas pour eux à mener une existence « mondaine »... ni même peut-être tout à fait « séculière ».

Les membres de ces groupes (prêtres séculiers - aussi dits diocésains -, laïcs hommes et femmes célibataires) exercent - la plupart des prêtres séculiers exceptés - des métiers profanes, vivent exceptionnellement en communautés, ne portent sur eux aucun signe distinctif -habillement ou autre. Leur formation spirituelle est assurée sans qu'ils quittent leurs activités ordinaires; les instituts procurent par ailleurs une formation continue à leurs membres; ceux-ci s'engagent par des «promesses", des «engagements", des "vœux» (le vocabulaire flotte) à pratiquer - selon leurs Constitutions propres approuvées par la hiérarchie catholique - les traditionnelles vertus des vœux religieux (pauvreté, chasteté, obéissance). La discrétion sur l'existence de ces groupes et l'appartenance des membres est fortement recommandée; en certaines circonstances, le secret a été la règle.

3 Il existe, dans l'univers et en 1997, 191 instituts séculiers, aux visées et aux spiritualités variées. $85 \%$ des membres de ces groupes sont des femmes. La France a donné naissance à 24 des 31 instituts qu'elle abrite. C'est en 1947 que le Saint-Siège a donné une première approbation officielle à ce genre de vie ; mais l'origine des groupements en question peut avoir été plus ancienne. Il en existe de cléricaux (recevant diacres, prêtres, évêques), d'autres formés - séparément - de laïcs célibataires - ou veufs/ veuves - de l'un ou l'autre sexe. Certains de ces groupements - de même spiritualité, et souvent, d'histoire parallèle - comportent l'ensemble des «branches » possibles, lesquelles demeurent autonomes cependant quant au gouvernement, à l'administration, aux activités et à la vie quotidienne. Toujours en 1997 et en France, les instituts séculiers rassemblent 3000 membres environ, parmi lesquels les femmes prédominent. On se situe là devant une «vocation rare ", spécialement s'agissant des laïcs célibataires.

4 L'ouvrage de M.-A.P. (on n'a pas su découvrir si « elle en est » ou pas) est la première étude du phénomène, mais dans ses groupes féminins exclusivement. Il s'agit d'une thèse d'histoire. De ce point de vue-là, elle fait un apport considérable, presque entièrement original, à la connaissance d'un genre de vie peu visible aux non "spécialistes ». Il semble que l'occasion de ce travail et de sa publication ait été fournie par la prise de conscience du " paradoxe » de la vocation aux instituts séculiers et de ses conséquences (cf. le titre du livre) éventuellement néfastes. N'est-on pas là - et selon les apparences - devant des "chrétiens comme les autres », qui prétendent première curiosité - mener une vie religieuse - ou quasiment telle - dans le monde, avec des visées apostoliques, fussent-elles discrètes, et qui - paradoxe - se doivent de ne pas se dévoiler pour ce qu'ils sont? Mais alors comment exercer son apostolat dans la lisibilité souhaitable, et se recruter facilement? D'autres formations pas nécessairement religieuses ont connu ce genre de problème. La baisse constatée - assez récemment - des vocations aux instituts séculiers de femmes - puisque c'est d'elles exclusivement qu'il s'agit ici - est, à ce qu'il semble, le déclencheur que nous cherchions au travail de M.-A.P. et à sa publication. Précisons-le - mais est-ce encore nécessaire? - il s'agit de tout autre chose que d'une brochure pieuse de propagande. 